\title{
Zinc-Induced Cortical Neuronal Death: Contribution of Energy Failure Attributable to Loss of $\mathrm{NAD}^{+}$and Inhibition of Glycolysis
}

\author{
Christian T. Sheline, M. Margarita Behrens, and Dennis W. Choi \\ Department of Neurology and Center for the Study of Nervous System Injury, Washington University School of Medicine, \\ St. Louis, Missouri 63110
}

Excessive zinc influx may contribute to neuronal death after certain insults, including transient global ischemia. In light of evidence that levels of intracellular free $\mathrm{Zn}^{2+}$ associated with neurotoxicity may be sufficient to inhibit glyceraldehyde-3phosphate dehydrogenase (GAPDH), experiments were performed looking for reduced glycolysis and energy failure in cultured mouse cortical neurons subjected to lethal $\mathrm{Zn}^{2+}$ exposure. As predicted, cultures exposed for 3-22 hr to $40 \mu \mathrm{M}$ $\mathrm{Zn}^{2+}$ developed an early increase in levels of dihydroxyacetone phosphate (DHAP) and fructose 1,6-bisphosphate (FBP) and a progressive loss of ATP levels, followed by neuronal cell death; furthermore, addition of the downstream glycolytic substrate pyruvate to the bathing medium attenuated the fall in ATP and neuronal death.

However, an alternative to direct $\mathrm{Zn}^{2+}$ inhibition of GAPDH was raised by the observation that $\mathrm{Zn}^{2+}$ exposure also induced

$\mathrm{Zn}^{2+}$ is an essential ion in mammalian cells. It is incorporated into the active site of many metalloenzymes (Vallee and Falchuk, 1993; Berg and Shi, 1996) and is probably used in the CNS as a neurotransmitter or neuromodulator (Frederickson, 1989). It is stored within vesicles in presynaptic boutons (Frederickson et al., 1983; Danscher et al., 1985) and is released together with glutamate by membrane depolarization in a $\mathrm{Ca}^{2+}$-dependent manner (Assaf and Chung, 1984; Howell et al., 1984; Charton et al., 1985). Although its precise role in neural signaling has not been defined, it may regulate neurotransmission by altering the function of several receptors and channels, including NMDA receptors, GABA receptors, glycine receptors, ATP receptors, and voltage-gated $\mathrm{Na}^{+}$and $\mathrm{Ca}^{2+}$ channels (Harrison and Gibbons, 1994; Smart et al., 1994). $\mathrm{Zn}^{2+}$ may also contribute to neuronal death in disease states, such as transient global ischemia or prolonged seizures (Choi and Koh, 1998). Brain ischemia triggers the translocation of presynaptic $\mathrm{Zn}^{2+}$ (over the ensuing 1-24 hr) into the soma of selectively vulnerable hippocampal CA1 neurons, as well as other vulnerable neurons in cortex, amygdala, striatum, and thalamus that later go on to die (Tonder et al., 1990; Koh et al., 1996). Both this translocation and subsequent selective neuronal cell death can be blocked by the administration of an

Received Oct. 25, 1999; revised Jan. 27, 2000; accepted Feb. 18, 2000.

This work was supported by National Institutes of Health, National Institute of Neurological Disorders and Stroke Grant NS 30337 (D.W.C.).

Correspondence should be addressed to Dennis W. Choi, Department of Neurology and Center for the Study of Nervous System Injury, Washington University School of Medicine, 660 South Euclid Avenue, St. Louis, MO 63110. E-mail: choid@neuro.wustl.edu.

Copyright (c) 2000 Society for Neuroscience $0270-6474 / 00 / 203139-08 \$ 15.00 / 0$ an early decrease in nicotinamide-adenine dinucleotide (NAD ${ }^{+}$) levels, an event itself capable of inhibiting GAPDH. Favoring this indirect mechanism of GAPDH inhibition, the neuroprotective effects of pyruvate addition were associated with normalization of cellular levels of $\mathrm{NAD}^{+}, \mathrm{DHAP}$, and FBP. $\mathrm{Zn}^{2+}$ induced neuronal death was also attenuated by addition of the energy substrate oxaloacetate, the activator of pyruvate dehydrogenase, dichloroacetate, or the inhibitors of NAD ${ }^{+}$catabolism, niacinamide or benzamide. Acetyl carnitine, $\alpha$-keto butyrate, lactate, and $\beta$-hydroxy-butyrate did not attenuate $\mathrm{Zn}^{2+}$ induced neurotoxicity, perhaps because they could not regenerate $\mathrm{NAD}^{+}$or be used for energy production in the presence of glucose.

Key words: pyruvate; niacinamide; energy depletion; PARS; ATP levels; GAPDH inhibition

extracellular chelator CaEDTA (Koh et al., 1996). The extracellular concentration of $\mathrm{Zn}^{2+}$ after intense neuronal activity may reach several hundred micromolar (Assaf and Chung, 1984), concentrations that are neurotoxic to cultured cortical neurons (Yokoyama et al., 1986; Choi and Koh, 1998).

It is presently unknown why exposure to high concentrations of extracellular $\mathrm{Zn}^{2+}$ can induce neuronal death. A critical first step appears to be entry across the plasma membrane, mediated by several routes, including voltage-gated calcium channels, agonistgated calcium channels, and reverse operation of the sodiumcalcium exchanger (Choi and Koh, 1998). We have used mag fura 5 to detect elevations in neuronal intracellular free $\mathrm{Zn}^{2+}$ $\left(\left[\mathrm{Zn}^{2+}\right]_{\mathrm{i}}\right)$ associated with zinc exposure under several conditions (Sensi et al., 1997). Although mag fura 5 is ratiometric and suitable for detecting early increases in $\left[\mathrm{Zn}^{2+}\right]_{\mathrm{i}}$, its high affinity $\left(\mathrm{K}_{\mathrm{D}}\right.$ of $\left.\sim 10^{-12}\right)$ may limit its ability to detect peak concentrations. Therefore we have recently used a low affinity $\left(K_{D}\right.$ of $\sim 1$ $\mu \mathrm{M} \mathrm{Zn}^{2+}$ ) non-ratiometric $\mathrm{Zn}^{2+}$-selective dye, Newport Green

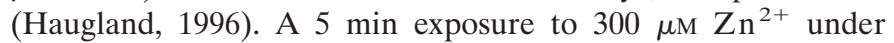
depolarizing conditions - an insult that triggers widespread cortical neuronal death over the next hr (Yokoyama et al., 1986) -resulted in $\left[\mathrm{Zn}^{2+}\right]_{\mathrm{i}}$ reaching $400-600 \mathrm{~nm}$ as assessed with Newport Green (Canzoniero et al., 1999; Sensi et al., 1999). At this concentration, $\mathrm{Zn}^{2+}$ can inhibit the key glycolytic enzyme glyceraldehyde-3-phosphate dehydrogenase (GAPDH) in solution, with $400 \mathrm{nM} \mathrm{Zn}^{2+}$ producing $50 \%$ inhibition of purified GAPDH (Krotkiewska and Banas, 1992). $\mathrm{Zn}^{2+}$ has also been reported to inhibit phosphofructokinase in solution, with an $\mathrm{IC}_{50}$ of $1.5 \mu \mathrm{M}$ in the presence of $60 \mu \mathrm{M}$ fructose 6-phosphate (Ikeda et al., 1980). 
Figure 1. Toxic levels of extracellular zinc do not block BDNF-induced signaling. Neuronal cultures were deprived of serum and treated in the absence $(S D)$ or presence of $40 \mu \mathrm{M} \mathrm{Zn}{ }^{2+}(Z n)$ with $100 \mathrm{ng} / \mathrm{ml} \mathrm{BDNF}$ for the indicated times. Cell extracts were prepared, and activation of the MAP kinase pathway was determined by Western blotting using antibodies that detect the phosphorylated form of ERK1 and ERK2 ( $p 44$ and $p 42$, respectively). We have quantified the bands using the $0.5 \mathrm{hr}$ plus BDNF, minus zinc as $100 \%$.

The purpose of the present study was to test the hypothesis that neurotoxic $\mathrm{Zn}^{2+}$ exposure leads to inhibition of GAPDH, resulting in a buildup of the upstream substrates dihydroxyacetone phosphate (DHAP) and fructose bisphosphate (FBP) and a fall in neuronal ATP levels. Furthermore, if GAPDH inhibition contributed importantly to the neurotoxic effects of $\mathrm{Zn}^{2+}$, we postulated that the administration of suitable downstream energy substrates might be neuroprotective against $\mathrm{Zn}^{2+}$ exposure.

Parts of this work have been published previously in abstract form (Sheline and Choi, 1997).

\section{MATERIALS AND METHODS}

Cell culture and toxicity studies. Near-pure neuronal cultures were prepared from embryonic day 15 (E15) mouse cortices as described previously (Sheline and Choi, 1998). Dissociated cortical neurons were taken from E15 Swiss-Webster mice and plated in Eagle's minimal essential medium (MEM) (Earle's salts, glutamine-free) containing $21 \mathrm{~mm}$ glucose, $5 \%$ fetal bovine serum, and $5 \%$ horse serum at a density of 5 hemispheres per plate onto poly-D-lysine-laminin-coated plates. At $3 \mathrm{~d}$ in vitro (DIV), cytosine arabinoside was added to $10 \mu \mathrm{M}$ to inhibit glial growth. Chronic toxicity studies were initiated by washing cultures four times with MEM containing $21 \mathrm{~mm}$ glucose, followed by exposure to $\mathrm{ZnCl}_{2}$ in the same media supplemented with $1 \mu \mathrm{M}(+)-5-$ methyl-10,11dihydro-5H-dibenzo [a,d] cycloheplen-5,10-imine maleate (MK-801) and $100 \mathrm{ng} / \mathrm{ml}$ of neurotrophin-4 (NT-4) or BDNF. MK-801 was included to prevent wash-induced activation of NMDA receptors and was not itself toxic over the ensuing $24 \mathrm{hr}$, and NT-4 or BDNF were included as a needed survival factor (serum could not be used because it chelates $\mathrm{Zn}^{2+}$ ). Acute toxicity studies were initiated by washing cultures four times with HEPES-buffered salt solution, followed by exposure to $\mathrm{ZnCl}_{2}$ in the same media supplemented with $1 \mu \mathrm{M}$ MK- 801 and $100 \mathrm{ng} / \mathrm{ml} \mathrm{NT}-4$ or BDNF as a survival-promoting activity in the presence or absence of $60 \mathrm{~mm} \mathrm{KCl}$ for 5 or $15 \mathrm{~min}$. The exposure was terminated by washing three times with MEM containing $21 \mathrm{mM}$ glucose, the cultures were put back into the same media supplemented with $1 \mu \mathrm{M}$ MK-801 and 100 $\mathrm{ng} / \mathrm{ml} \mathrm{NT}-4$ or BDNF as a survival-promoting activity, and cell death was assayed $24 \mathrm{hr}$ later. Near-pure neuronal cultures were washed seven times using salt solution (same as in MEM) without glucose but in the presence of $1 \times$ amino acids before testing the use of different energy substrates at $6 \mathrm{~mm}$ in the same glucose-free solution plus MK-801 and NT-4 for $24 \mathrm{hr}$. These same substrates were tested against $40 \mu \mathrm{M} \mathrm{Zn}{ }^{2+}$ exposure, as were the effects of late addition of pyruvate. Cell death was estimated by phase-contrast microscopy after staining with $0.01 \%$ trypan blue for $60 \mathrm{~min}$ at $37^{\circ} \mathrm{C}$ and assessed quantitatively by measuring lactate dehydrogenase (LDH) efflux (Koh and Choi, 1987) or propidium iodide fluorescence (Sheline and Choi, 1998) and comparing it with the complete neuronal death induced by exposure to $20 \mu \mathrm{M}$ A23187 for $24 \mathrm{hr}$.

Determination of dihdroxyacetone phosphate, lactate, and ATP levels. Near-pure neuronal cultures (8-9 DIV) were used for the ATP measurements. Cultures were lysed by addition of $0.1 \mathrm{~m} \mathrm{NaOH}-1 \mathrm{~mm}$ EDTA at the indicated time points. After centrifugation at $13,000 \times g$, the supernatant was neutralized and protein was precipitated by addition of $100 \mu \mathrm{l}$ of $0.5 \mathrm{M}$ perchloric acid. ATP was measured by the luciferin-luciferase luminescence assay and was normalized to sham-washed controls and to protein content as determined by the bichichonic acid assay (Lust et al., 1981). DHAP, FBP, and extracellular lactate measurements were made on neuronal cell lysates or the bathing medium (for extracellular lactate) prepared in a similar manner, but were lysed by addition of $6 \%$ perchloric acid and protein precipitated by addition of potassium carbonate to $\mathrm{pH}$ 3.5. DHAP was measured by its enzymatic conversion to glycerol-3phosphate by glycerol-3-phosphate dehydrogenase, and the concomitant
SD

\section{BDNF (100 ng/ml)}

Zn

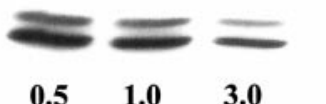

0

0.5

1.0

3.0

(1)

$\mathbf{0}$

$100 \%$

73

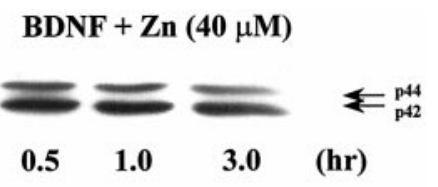

9280 oxidation of nicotinamide-adenine dinucleotide, reduced form (NADH) was measured spectrophotometrically. Glyceraldehyde 3-phosphate was subsequently measured in a linked reaction by its enzymatic conversion to DHAP by triosephosphate isomerase, followed by addition of aldolase to measure FBP levels (Michal, 1974). Extracellular lactate concentration was measured by its conversion to pyruvate in the presence of excess hydrazine, nicotinamide-adenine dinucleotide $\left(\mathrm{NAD}^{+}\right)$, and $\mathrm{LDH}$ to drive the production of NADH (Gutmann and Wahlefeld, 1974). Other metabolites were also measured by their enzymatic conversion and the concomitant oxidation or reduction of NADH, NAD ${ }^{+}$, or nicotinamideadenine dinucleotide phosphate (NADP ${ }^{+}$).

Determination of $\mathrm{NAD}^{+}$and $\mathrm{NADH}$ levels. Neuronal cultures (8-9 DIV) were used for the $\mathrm{NAD}^{+}$and NADH measurements. For the $\mathrm{NAD}^{+}$and NADH measurements, cultures were lysed by addition of 75\% ethanol-0.05 м K2HPO4 after a $4 \mathrm{hr} 40 \mu \mathrm{M} \mathrm{Zn}{ }^{2+}$ exposure. Protein was precipitated by addition of $\mathrm{ZnCl}_{2}$ to $20 \mathrm{~mm}$ and centrifuged at $13,000 \times g$, and the supernatant was assayed for $\mathrm{NAD}^{+}$and $\mathrm{NADH}$ levels (Tilton et al., 1991). NAD ${ }^{+}$in the supernatant was measured after its enzymatic conversion to NADH by alcohol dehydrogenase, resulting in an increase in the fluorescence spectrum between 400 and $600 \mathrm{~nm}$ after an excitation at $340 \mathrm{~nm}$ using a Perkin-Elmer (Emeryville, CA) LS $50 \mathrm{~B}$. NADH was measured by the difference in the fluorescence spectrum between 400 and $600 \mathrm{~nm}$ before and after treatment of the supernatant with lactate dehydrogenase (Sander et al., 1976).

Whole-cell lysates. Neuronal cultures (8 DIV) were serum-deprived for $1 \mathrm{hr}$ and then exposed as indicated to $100 \mathrm{ng} / \mathrm{ml} \mathrm{BDNF}$ in the presence or absence of $40 \mu \mathrm{M} \mathrm{Zn}{ }^{2+}$. The cells were then washed twice with ice-cold PBS and resuspended in cold buffer A $(1 \%$ NP-40, $20 \mathrm{~mm}$ Tris-Cl, $\mathrm{pH} 7.5,10 \mathrm{~mm}$ EGTA, $40 \mathrm{~mm} \beta$-glycerophosphate, $2.5 \mathrm{~mm}$ $\mathrm{MgCl}_{2}, 2 \mathrm{~mm}$ orthovanadate, $1 \mathrm{~mm}$ dithiothreitol, $1 \mathrm{~mm}$ phenyl-methylsulfonylfluoride, $20 \mu \mathrm{g} / \mathrm{ml}$ aprotinin, and $20 \mu \mathrm{g} / \mathrm{ml}$ leupeptin) for $15 \mathrm{~min}$.

Lysates were centrifuged at $15000 \times g$ for $5 \mathrm{~min}$, and supernatants were retained for analysis. Protein concentrations were determined by the bicinchoninic acid method (Pierce, Rockford, IL) using bovine serum albumin as standard.

Western blotting. For Western blots, $25 \mu \mathrm{g}$ of total cell protein were resolved in $8 \%$ SDS-PAGE gels, transferred to nitrocellulose membranes (MSI, Westboro, MA), and incubated with antibodies specific for phospho-ERKs [anti-active mitogen-activated protein kinase (MAPK) antibodies; New England Biolabs, Beverly, MA]. Bound antibodies were detected by the enhanced chemiluminescence method (Amersham Pharmacia Biotech, Arlington Heights, IL).

Reagents. Most reagents were from Sigma (St. Louis, MO). The neurotrophins NT-4 and BDNF were the kind gift of Amgen (Thousand Oaks, CA).

\section{RESULTS}

\section{Zinc exposure did not block neurotrophin signaling}

A previous study in PC12 cells suggested that $\mathrm{Zn}^{2+}$ can alter the conformation and biological activities of several neurotrophins (Ross et al., 1997). Arguing against the possibility that $\mathrm{Zn}^{2+}$ induced neuronal death is mediated by an acute loss of neurotrophin influence, ATP depletion and neuronal death occurred more quickly after $\mathrm{Zn}^{2+}$ exposure than after serum deprivation (data not shown; see Figs. 3, 5). Furthermore, $40 \mu \mathrm{M} \mathrm{Zn}{ }^{2+}$ did not prevent $100 \mathrm{ng} / \mathrm{ml}$ BDNF or NT-4 from initiating the TrkBmediated signaling cascade resulting in phosphorylation of the ERK family of protein kinases (Fig. 1). 
Table 1. Zinc exposure selectively increased DHAP and FBP levels, and this increase was reversed by addition of pyruvate or niacinamide

\begin{tabular}{lcclll} 
(Nanomoles/plate \pm SEM) & Control & $40 \mu \mathrm{M} \mathrm{Zinc}$ & $\begin{array}{l}\text { Zinc } \\
\text { pyruvate }\end{array}$ & $\begin{array}{l}\text { Zinc }+ \text { niaci- } \\
\text { namide }\end{array}$ & Staurosporine \\
\hline Glucose-6-phosphate & $4.2 \pm 0.6$ & $7.6 \pm 1.0$ & N.P. & N.P. & N.P. \\
Fructose-6-phosphate & $1.6 \pm 0.2$ & $3.2 \pm 0.4$ & N.P. & N.P. & N.P. \\
DHAP & $5.2 \pm 0.6$ & $22.4 \pm 0.8^{*}$ & $5.2 \pm 0.6 \#$ & $5.0 \pm 0.6 \#$ & $3.2 \pm 2.2$ \\
Fructose bisphosphate & $5.2 \pm 0.8$ & $51.4 \pm 5.0^{*}$ & $5.0 \pm 0.8 \#$ & $11.2 \pm 1.4 \#$ & $5.8 \pm 0.6$ \\
2-Phospho-glycerate & $6.25 \pm 0.5$ & $11.7 \pm 0.5^{*}$ & N.P. & N.P. & N.P. \\
Phospho-enolpyruvate & $5.75 \pm 1.7$ & $8.2 \pm 4.7$ & N.P. & N.P. & N.P. \\
Pyruvate & $14.2 \pm 2.2$ & $20 \pm 4.5$ & N.P. & N.P. & N.P.
\end{tabular}

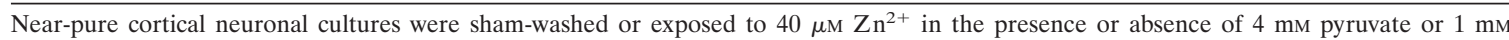
niacinamide. The cells were then harvested and assayed for levels of the indicated glycolytic intermediates (results were pooled from three separate experiments; $n=5-8$ cultures per condition). Exposure to $100 \mathrm{~nm}$ staurosporine for $4-6 \mathrm{hr}$, sufficient to trigger widespread apoptosis, did not mimic the ability of $\mathrm{Zn}^{2+}$ to elevate DHAP or FBP. N.P. indicates that the experiment was not performed. * signifies difference from sham-washed controls, and \# signifies difference from $\mathrm{Zn}^{2+}$-treated cultures at $p<0.05$ by one-way ANOVA, followed by a Bonferroni test.

\section{Zinc exposure increased neuronal levels of DHAP and FBP}

Near-pure cortical neuronal cultures, 8-9 d in vitro, were exposed

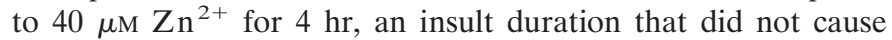
cellmembrane failure as measured by $\mathrm{LDH}$ efflux to the bathing medium (see below) or staining with trypan blue or propidium iodide (data not shown). At that time, cells were lysed, and the lysate was assayed for DHAP, FBP, fructose 6-phosphate, glucose 6-phosphate, pyruvate, phosphoenolpyruvate, and glycerate 2-phosphate. Both DHAP and FBP levels were increased severalfold, whereas other measured metabolites (except 2-phosphoglycerate) were unchanged (Table 1). Glyceraldehyde 3-phosphate was undetectable in either control cultures or cultures exposed to $\mathrm{Zn}^{2+}$, most likely because it was preferentially converted into DHAP (Lehninger et al., 1993).

In contrast, when the neuronal cultures were exposed to $100 \mathrm{nM}$ staurosporine for $6 \mathrm{hr}$, an exposure capable of triggering programmed cell death (Koh et al., 1995; Weil et al., 1996), no changes were seen in the above metabolites (Table 1).

\section{Zinc-induced neuronal death was attenuated by pyruvate}

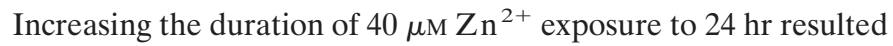
in widespread neuronal degeneration, most marked initially in processes, and later accompanied by trypan blue staining (Fig. 2) and release of $\mathrm{LDH}$ to the bathing medium (Fig. 3). Addition of 2-6 mM pyruvate to the bathing medium during this toxic $\mathrm{Zn}^{2+}$ exposure resulted in a concentration-dependent reduction in neuronal death, with near-complete preservation of neurons produced by $6 \mathrm{~mm}$ pyruvate (Figs. 2, 3A). Pyruvate ( $4 \mathrm{~mm}$ ) attenuated the neuronal death induced by $24 \mathrm{hr}$ exposure to $\mathrm{Zn}^{2+}$ concentrations between 20 and $100 \mu \mathrm{M}$ (Fig. 3B), even if added in a
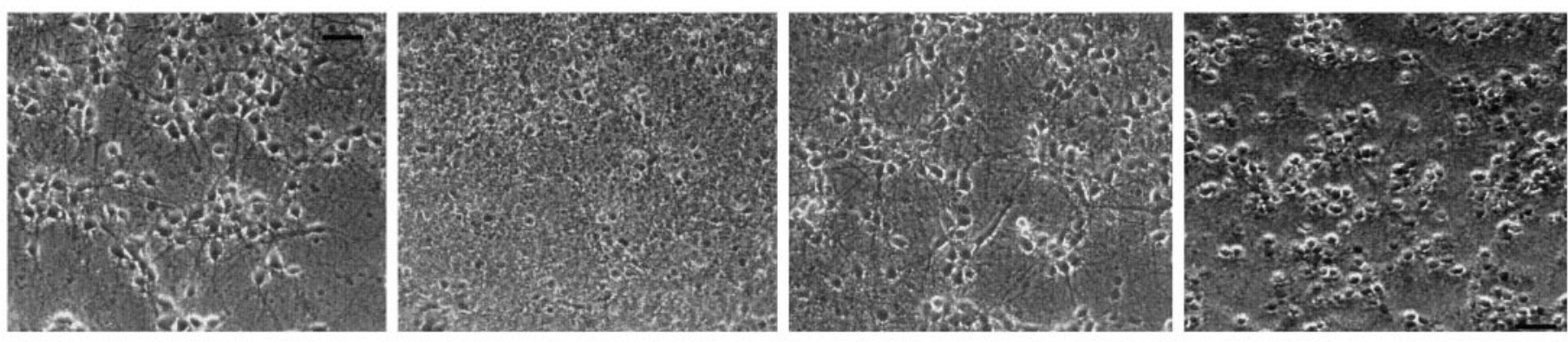

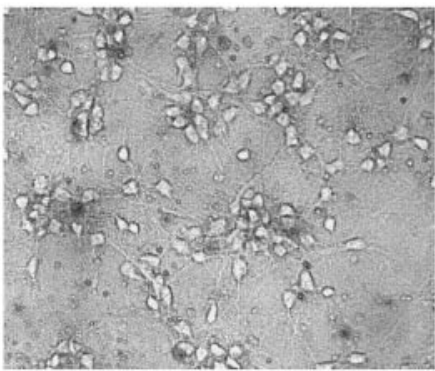

Control

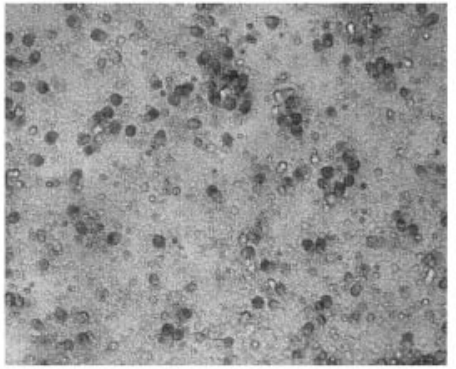

Zinc

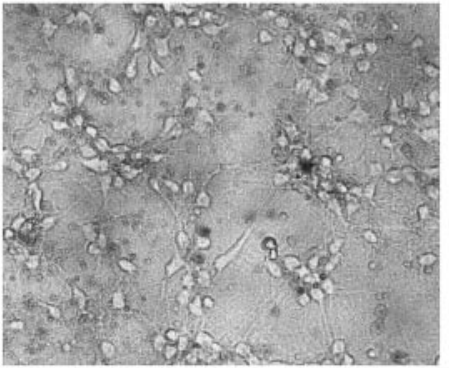

Zinc + Pyruvate

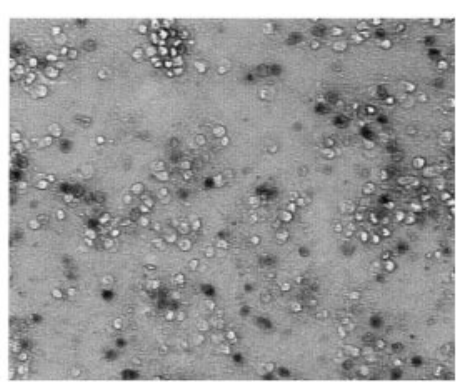

Zinc + Niacinamide

Figure2. Zinc-induced neuronal death is attenuated by pyruvate. Phase-contrast (top) and matched bright-field fields after staining with trypan blue (bottom) were taken in near-pure neuronal cultures $24 \mathrm{hr}$ after exposure to sham wash (Control), $40 \mu \mathrm{M} \mathrm{Zn^{2+ }}$, or $40 \mu \mathrm{M} \mathrm{Zn}{ }^{2+}$ in the presence of $4 \mathrm{~mm}$ pyruvate or $1 \mathrm{~mm}$ niacinamide. Scale bar, $50 \mu \mathrm{m}$. 
A.

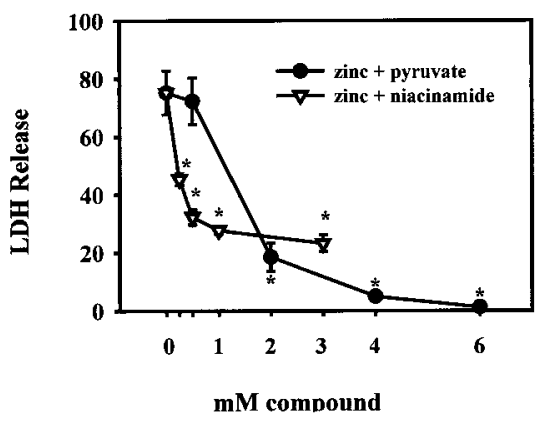

B.

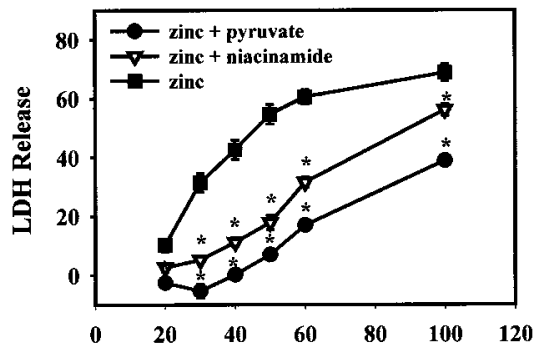

$\mu$ M Zinc

C.

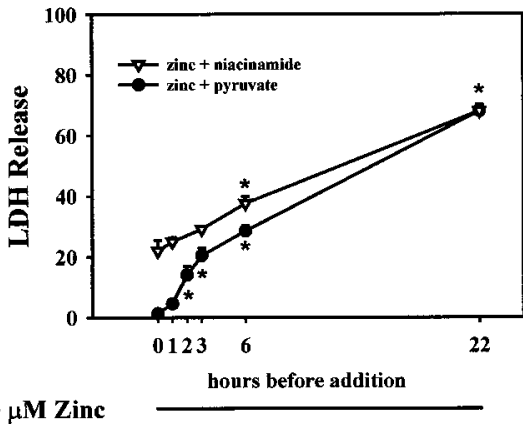

Figure 3. Inhibition of slow zinc toxicity by pyruvate or niacinamide. $A$, Neuronal cultures were exposed to $40 \mu \mathrm{M} \mathrm{Zn}{ }^{2+}$ for $24 \mathrm{hr}$ in the presence of the indicated concentrations of pyruvate and niacinamide, and cell death was assessed by LDH release to the bathing medium (mean + SEM, $n=9-12$ cultures per condition), scaled to the level associated with near-complete neuronal death (produced by exposure to $20 \mu \mathrm{M}$ A23187 for $24 \mathrm{hr}, 100 \%)$. ${ }^{*} p<0.05$ indicates difference from $\mathrm{Zn}^{2+}$ exposure alone by one-way ANOVA, followed by a Bonferroni test. $B$, Neuronal cultures were exposed to the indicated concentrations of $\mathrm{Zn}^{2+}$ for $24 \mathrm{hr}$ in the presence or absence of $4 \mathrm{~mm}$ pyruvate or $3 \mathrm{~mm}$ niacinamide. ${ }^{*} p<$ 0.05 indicates difference from $\mathrm{Zn}^{2+}$ exposure alone at the same time point. $C, \mathrm{Zn}^{2+}(40 \mu \mathrm{M})$ was added to the bathing medium at time 0 , and afterwards, at the indicated times, $4 \mathrm{~mm}$ pyruvate or $3 \mathrm{~mm}$ niacinamide were added. Cell death was measured at $22 \mathrm{hr} .{ }^{*} p<0.05$ signifies difference from addition at time 0 .

delayed manner 3-6 hr after the onset of $\mathrm{Zn}^{2+}$ exposure (Fig. $3 C)$. The neuroprotective effect of pyruvate addition was well maintained for at least $48 \mathrm{hr}$ after the onset of $\mathrm{Zn}^{2+}$ exposure.

The more fulminant form of $\mathrm{Zn}^{2+}$ toxicity induced by brief (5-15 min) exposure to high concentrations of $\mathrm{Zn}^{2+}$ (100-400 $\mu \mathrm{M})$ in the presence of $60 \mathrm{mM} \mathrm{K}^{+}$[to depolarize cells and enhance entry through voltage-gated calcium channels (Weiss et al., 1993; Sensi et al., 1997)] could also be partially attenuated by $10 \mathrm{~mm}$ pyruvate or niacinamide (Fig. 4).

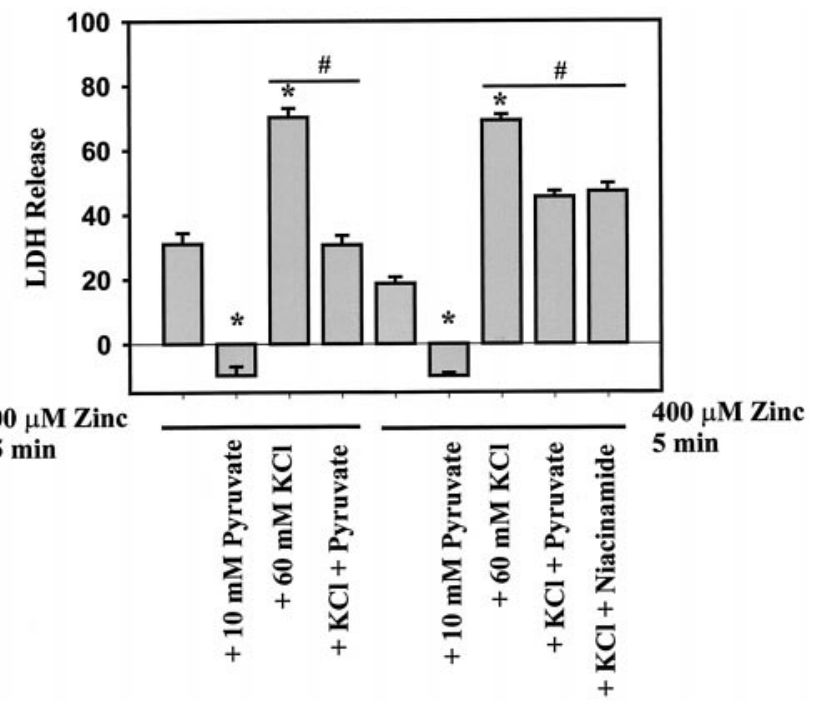

Figure 4. Inhibition of fast zinc toxicity by pyruvate or niacinamide.

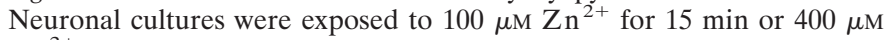
$\mathrm{Zn}^{2+}$ for $5 \mathrm{~min}$ in the presence or absence of $60 \mathrm{~mm} \mathrm{KCl}$, with $10 \mathrm{~mm}$ pyruvate or $10 \mathrm{~mm}$ niacinamide present $1 \mathrm{hr}$ before, during, and $24 \mathrm{hr}$ afterwards as indicated. Neuronal death was determined $24 \mathrm{hr}$ after the onset of $\mathrm{Zn}^{2+}$ exposure by LDH efflux ( $n=9-12$ cultures per condition). ${ }^{*} p<0.05$ signifies difference from $\mathrm{Zn}^{2+}$ exposure alone. $\# p<0.05$ signifies difference associated with pyruvate or niacinamide addition on neuronal death induced by $\mathrm{Zn}^{2+}$ plus $\mathrm{KCl}$.
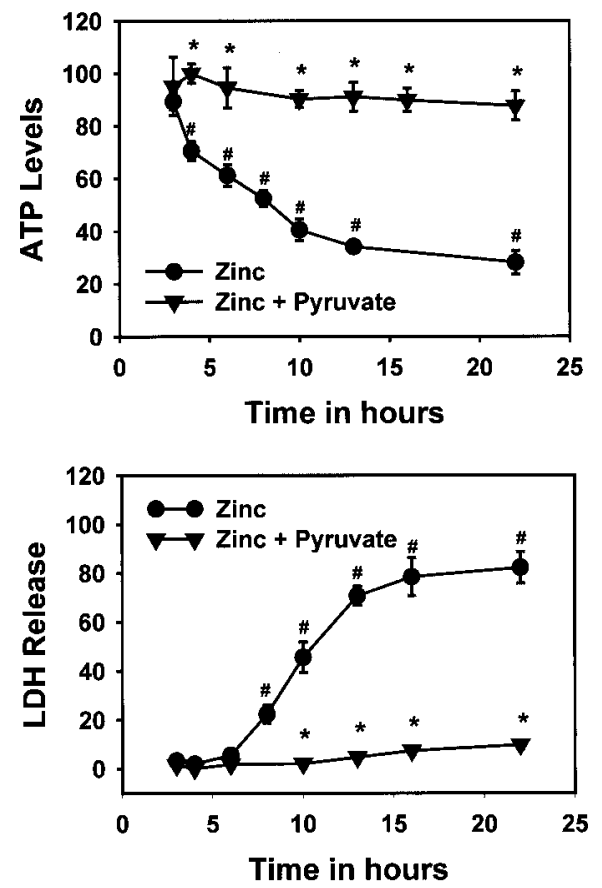

Figure 5. Time course of neuronal cell death and ATP depletion during exposure to zinc with or without pyruvate. Neuronal cultures were exposed continuously to $40 \mu \mathrm{M} \mathrm{Zn}{ }^{2+}$ in the presence or absence of $4 \mathrm{~mm}$ pyruvate, and cellular ATP levels (top) or LDH release (bottom) were determined at the indicated times. Cell death was determined by LDH release to the bathing medium (scaled to signal associated with complete neuronal death induced by $24 \mathrm{hr}$ exposure to $20 \mu \mathrm{M}$ A23187, set as 100). ATP loss was determined by comparison with levels measured in shamwashed controls. Error bars in both parts are SEM; $n=9-12$ cultures per condition, pooled from three independent experiments. ${ }^{*} p<0.05$ signifies difference from $\mathrm{Zn}^{2+}$ exposure alone by two-way ANOVA, followed by a Bonferroni test. \#p $<0.05$ signifies difference from sham-washed controls by two-way ANOVA, followed by a Bonferroni test. 


\begin{tabular}{|c|c|c|c|}
\hline Condition & $\begin{array}{l}\mathrm{NAD}^{+} \\
\text {(nmol/plate) }\end{array}$ & $\begin{array}{l}\text { NADH } \\
\text { (nmol/plate) }\end{array}$ & $\begin{array}{l}\text { Lactate } \\
\text { (nmol/plate) }\end{array}$ \\
\hline Control & $4.63 \pm 0.31$ & $0.58 \pm 0.052$ & $2020 \pm 130$ \\
\hline Control $+4 \mathrm{~mm}$ pyruvate & $5.62 \pm 0.59^{*}$ & $0.20 \pm 0.016^{*}$ & $2930 \pm 110^{*}$ \\
\hline Control $+1 \mathrm{~mm}$ niacinamide & $6.170 \pm 0.36^{*}$ & $0.66 \pm 0.058$ & $2650 \pm 230^{*}$ \\
\hline $40 \mu \mathrm{M}$ Zinc & $1.36 \pm 0.16^{*}$ & $0.83 \pm 0.14$ & $2470 \pm 80^{*}$ \\
\hline $40 \mu \mathrm{M}$ Zinc $+4 \mathrm{~mm}$ pyruvate & $4.86 \pm 0.22 \#$ & $0.042 \pm 0.027 \#$ & $3600 \pm 140 \#$ \\
\hline $40 \mu \mathrm{M}$ Zinc $+1 \mathrm{~mm}$ niacinamide & $4.38 \pm 0.40 \#$ & $0.89 \pm 0.059$ & $3270 \pm 170 \#$ \\
\hline
\end{tabular}

Neuronal cultures $\left(6 \times 10^{6}\right.$ cells per plate) were sham-washed (Control) or exposed to $40 \mu \mathrm{M} \mathrm{Zn}^{2+}$ in the presence or absence of $4 \mathrm{~mm}$ pyruvate or $1 \mathrm{~mm}$ niacinamide for $4 \mathrm{hr}$, after which the cells were harvested and assayed for levels of NAD ${ }^{+}$, NADH, or extracellular lactate (results are pooled from three separate experiments; $n=5-8$ cultures per condition). * signifies difference from sham-washed controls at $p<0.05$ by two-way ANOVA, followed by a Bonferroni test. \# signifies difference from $\mathrm{Zn}^{2+}$-treated cultures at $p<0.05$.

\section{Zinc-induced ATP depletion preceded cell death, and both were sensitive to pyruvate}

Neuronal cultures were exposed to $40 \mu \mathrm{M} \mathrm{Zn}^{2+}$ for 3-22 hr, with LDH efflux and ATP levels assessed at intermediate time points. ATP loss was detectable after $4 \mathrm{hr}$, whereas cell death measured by $\mathrm{LDH}$ release was not detectable until after $8 \mathrm{hr}$ (Fig. 5). Cell death assessed by propidium iodide staining was not detectable until after $6 \mathrm{hr}$ of $\mathrm{Zn}^{2+}$ exposure (data not shown). The addition of $4 \mathrm{~mm}$ pyruvate to the bathing medium blocked both ATP loss and cell death (Fig. 5).

\begin{tabular}{|c|c|c|}
\hline \multicolumn{3}{|c|}{$\begin{array}{l}\text { Table 3. Effect of selected energy substates, } \mathrm{NAD}^{+} \text {catabolism } \\
\text { inhibitors, or cofactors for pyruvate dehydrogenase against zinc } \\
\text { neurotoxicity or glucose deprivation-induced neuronal death }\end{array}$} \\
\hline$\%$ Cell death & $40 \mu \mathrm{M}$ Zinc & $\begin{array}{l}\text { Glucose } \\
\text { deprivation }\end{array}$ \\
\hline No addition & $67.7 \pm 2.8 \%$ & $89.6 \pm 4.7 \%$ \\
\hline$+3 \mathrm{~mm}$ Pyruvate & $0.3 \pm 1.9 \% *$ & $5.2 \pm 2.8 \% *$ \\
\hline$+3 \mathrm{~mm}$ Pyruvate $+3 \mathrm{~mm} \mathrm{CIN}$ & $61.2 \pm 4.1 \% \#$ & $76.5 \pm 5.9 \% \#$ \\
\hline$+3 \mathrm{~mm}$ Pyruvate $+20 \mathrm{~mm}$ oxamate & $47.9 \pm 2.7 \% \#$ & $25.7 \pm 2.8 \% \#$ \\
\hline$+3 \mathrm{~mm}$ Oxaloacetate & $1.6 \pm 0.9 \% *$ & $17.4 \pm 1.7 \% *$ \\
\hline+6 mм Malate & $37.3 \pm 1.8 \% *$ & $67.6 \pm 4.3 \% *$ \\
\hline$+6 \mathrm{~mm}$ Succinate & $48.8 \pm 2.4 \% *$ & $77.4 \pm 2.1 \% *$ \\
\hline$+6 \mathrm{~mm}$ Lactate & $67.8 \pm 3.5 \%$ & $3.4 \pm 2.3 \% *$ \\
\hline+6 mм $\beta$-Hydroxy-butyrate & $73.1 \pm 4.9 \%$ & $12.9 \pm 1.5 \% *$ \\
\hline$+6 \mathrm{mM} \alpha$-Keto-butyrate & $61.3 \pm 3.4 \%$ & $90.3 \pm 4.3 \%$ \\
\hline$+2 \mathrm{~mm}$ FBP & $59.1 \pm 5.1 \%$ & $68.6 \pm 1.4 \% *$ \\
\hline$+2 \mathrm{mM}$ DHAP & $62.3 \pm 4.1 \%$ & $30.7 \pm 4.8 \% *$ \\
\hline$+6 \mathrm{~mm}$ Acetyl-carnitine & $75.0 \pm 4.0 \%$ & $99.0 \pm 2.8 \%$ \\
\hline+3 mм Niacinamide & $15.1 \pm 1.6 \% *$ & $86.9 \pm 1.4 \%$ \\
\hline +3 mм Benzamide & $21.1 \pm 2.9 \% *$ & $77.9 \pm 3.9 \%$ \\
\hline +3 mм 3-Aminobenzamide & $24.0 \pm 3.7 \% *$ & $83.8 \pm 1.7 \%$ \\
\hline +6 mM Dichloroacetate & $21.4 \pm 1.6 \% *$ & $79.0 \pm 3.6 \%$ \\
\hline +2 mM Riboflavin & $65.4 \pm 3.5 \%$ & $83.3 \pm 2.0 \%$ \\
\hline$+6 \mathrm{~mm}$ Thiamine & $67.0 \pm 1.7 \%$ & $84.4 \pm 1.7 \%$ \\
\hline +0.05 mM Lipoic acid (reduced) & $69.4 \pm 2.4 \%$ & $105.8 \pm 1.7 \%$ \\
\hline+0.25 mM Lipoic amide & $60.2 \pm 2.4 \%$ & $89.8 \pm 1.4 \%$ \\
\hline
\end{tabular}

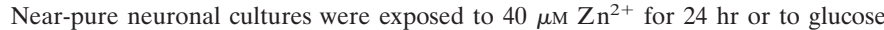
deprivation for $24 \mathrm{hr}$ alone or in the presence of the indicated compounds (titrated to optimal concentrations; data not shown), and cell death was determined by LDH efflux or propidium iodide fluorescence. $n=9-12$ cultures per condition. $*$ indicates difference from no addition and \# indicates difference from exposure plus pyruvate at $p<0.05$. CIN, cinnamic acid.

\section{Zinc-induced decrease in $\mathrm{NAD}^{+}$was attenuated by pyruvate or niacinamide}

Although the above observations were consistent with the hypothesis that direct inhibition of GAPDH by $\mathrm{Zn}^{2+}$ contributed importantly to the neurotoxic effects of the latter, unexpectedly, inclusion of $4 \mathrm{~mm}$ pyruvate during $\mathrm{Zn}^{2+}$ exposure abolished the buildup of DHAP and FBP found in cultures exposed to $\mathrm{Zn}^{2+}$ alone (Table 1).

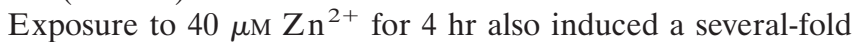
decrease in $\mathrm{NAD}^{+}$levels without a compensatory increase in NADH levels, as well as an increase in lactate. The inclusion of 4 mM pyruvate to the $\mathrm{Zn}^{2+}$ exposure abolished the decrease in $\mathrm{NAD}^{+}$, perhaps at the expense of NADH, and further increased lactate (Table 2). In addition, inclusion of 1-3 mM niacinamide, benzamide or 3-aminobenzamide, competitive inhibitors of $\mathrm{NAD}^{+}$-catabolizing enzymes (for review, see Szabo and Dawson, 1998), blocked the drop in $\mathrm{NAD}^{+}$levels and associated neuronal death (Tables 2, 3; data not shown).

\section{Effect of other energy substrates, NAD ${ }^{+}$catabolism inhibitors, or pyruvate dehydrogenase cofactors on zinc-induced neuronal death or glucose deprivation-induced death}

Other energy substrates, $\mathrm{NAD}^{+}$catabolism inhibitors, and pyruvate dehydrogenase $(\mathrm{PDH})$ cofactors [pyruvate, oxaloacetate, malate, succinate, lactate, $\beta$-hydroxy-butyrate, $\alpha$-keto-butyrate, FBP, DHAP, acetyl-carnitine, niacinamide, benzamide, 3-aminobenzamide, dichloroacetate (DCA), riboflavin, thiamine, lipoic acid, and lipoic amide] were tested at optimal concentrations (concentration titration data not shown) for their ability to reduce $\mathrm{Zn}^{2+}$-induced or glucose deprivation-induced neuronal death. At these concentrations, none of the compounds were found to be toxic or to induce gross changes in cell volume. Oxaloacetate, niacinamide, benzamide, and 3-aminobenzamide were nearly as effective as pyruvate at attenuating $\mathrm{Zn}^{2+}$-induced neuronal death, but of these, only pyruvate and oxaloacetate were used as energy substrates (Table 3). Niacinamide, benzamide, and 3-aminobenzamide competitively inhibit all $\mathrm{NAD}^{+}$-catabolizing enzymes; niacinamide is also a precursor for $\mathrm{NAD}^{+}$synthesis (for review, see Szabo and Dawson, 1998). In addition, DCA, which functions as an activator of the PDH complex (inhibiting the kinase that inhibits the complex), partially attenuated $\mathrm{Zn}^{2+}$ neurotoxicity without serving as an energy substrate. However, the other PDH complex cofactors, thiamine or lipoic acid, were ineffective against $\mathrm{Zn}^{2+}$ neurotoxicity. The effect of DCA was 


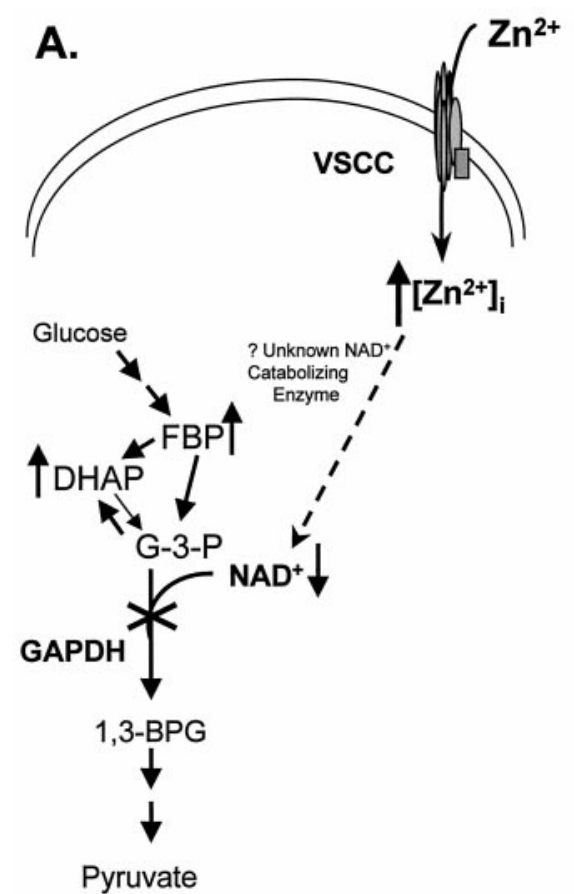

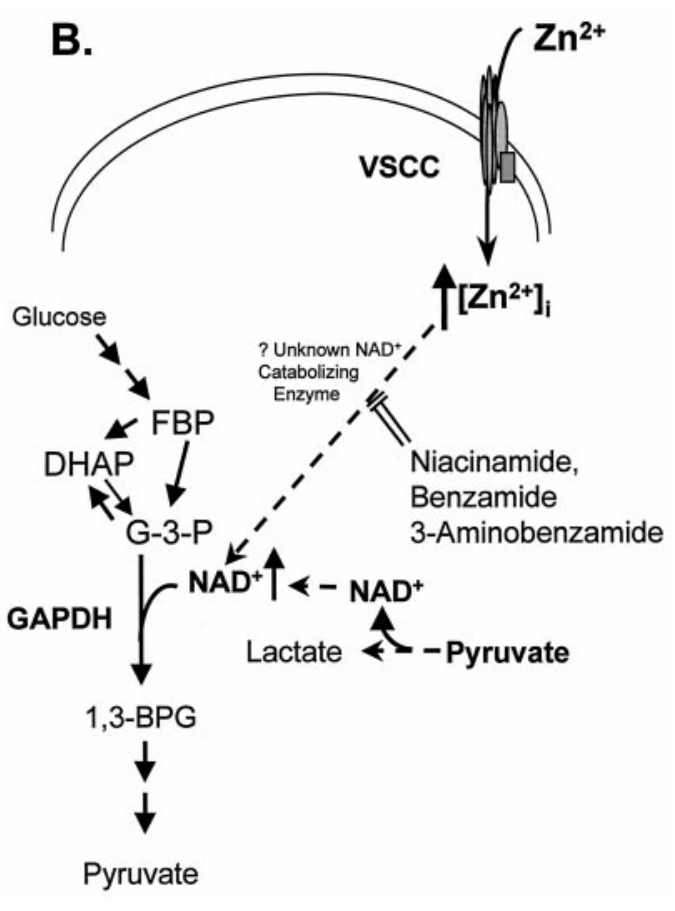

Figure 6. Summary model for $\mathrm{Zn}^{2+}$ induced neuronal death in vitro. VSCC, Voltage-sensitive calcium channel; $G-3-P$, glyceraldehyde-3-phosphate;1,3- $B P G, 1,3$ bisphosphoglycerate. $A$, The model for $\mathrm{Zn}^{2+}$-induced changes. $B$, The protective mechanisms for niacinamide, 3-aminobenzamide, and benzamide involve inhibition of an unknown $\mathrm{NAD}^{+}$catabolizing enzyme, thereby maintaining $\mathrm{NAD}^{+}$levels; the protective mechanism for pyruvate involves maintaining $\mathrm{NAD}^{+}$levels through its conversion to lactate. synergistic with low levels of pyruvate (data not shown). The protective effect of pyruvate was attenuated by cinnaminic acid, an inhibitor of the monocarboxylate transporter (Schurr et al., 1997), and by oxamate, a competitive inhibitor of lactate dehydrogenase (Wong et al., 1997). These results are summarized in the proposed model for $\mathrm{Zn}^{2+}$-induced neurotoxicity (Fig. 6). Compounds that could not be converted to pyruvate or serve as energy substrates or PDH complex cofactors in neuronal cultures did not attenuate $\mathrm{Zn}^{2+}$-induced neuronal death (Table 3). Two substrates differed in their ability to protect against glucose deprivation-induced death versus $\mathrm{Zn}^{2+}$-induced death. Lactate and $\beta$-hydroxy-butyrate protected against the former but not the latter.

\section{DISCUSSION}

We observed that neurotoxic levels of $\mathrm{Zn}^{2+}$ exposure induced in cortical neurons an early increase in glycolytic intermediates preceding GAPDH, followed by a progressive loss of ATP levels and neuronal cell death. Addition of the downstream glycolytic substrate pyruvate to the bathing medium attenuated both the fall in ATP and neuronal death. Simple chelation of $\mathrm{Zn}^{2+}$ by pyruvate is unlikely because the log stability constant for $\mathrm{Zn}^{2+}$ pyruvate is 1.3 (Martell and Smith, 1995), and reduction of neuronal death was also achieved by adding another downstream energy substrate, oxaloacetate, or the activator of pyruvate dehydrogenase, dichloroacetate. These findings are consistent with our initial hypothesis that a key mechanism of $\mathrm{Zn}^{2+}$ neurotoxicity is energy loss attributable to inhibition of glycolysis at GAPDH, an event that could be mediated directly by $\mathrm{Zn}^{2+}$ (see above). In nondividing bacterial cells, GAPDH has the largest control strength of all the glycolytic enzymes for metabolic regulation (Poolman et al., 1987). We have demonstrated previously that chemical inhibition of GAPDH with $\alpha$-monochlorohydrin can induce cultured cortical neurons to undergo apoptosis (Sheline and Choi, 1998), an event induced by levels of $\mathrm{Zn}^{2+}$ exposure (20-35 $\mu \mathrm{M})$ comparable with those used in the present experi- ments (D. Lobner and D. W. Choi, unpublished observations) (Y. H. Kim et al., 1999a).

However unexpectedly, $\mathrm{Zn}^{2+}$ exposure also induced an early fall in NAD ${ }^{+}$levels, an event itself capable of inhibiting GAPDH (Rovetto et al., 1975; Tilton et al., 1991). Favoring indirect inhibition of GAPDH caused by loss of NAD ${ }^{+}$, the neuroprotective effects of pyruvate addition were associated with normalization of cellular levels of $\mathrm{NAD}^{+}$and glycolytic intermediates preceding GAPDH. The latter event would not be expected to occur if GAPDH was directly inhibited by $\mathrm{Zn}^{2+}$. Also favoring a central role for $\mathrm{Zn}^{2+}$-induced depression of $\mathrm{NAD}^{+}$levels in triggering neuronal death, the fall in $\mathrm{NAD}^{+}$and neuronal death induced by $\mathrm{Zn}^{2+}$ was attenuated by the $\mathrm{NAD}^{+}$catabolism inhibitors niacinamide, benzamide, or 3-aminobenzamide (for review, see Szabo and Dawson, 1998).

One postulated mechanism of $\mathrm{Zn}^{2+}$ neurotoxicity is inhibition of mitochondrial electron transport (Skulachev et al., 1967; Link and von Jagow, 1995; Manev et al., 1997); this inhibition would decrease neuronal $\mathrm{NAD}^{+}$levels. However, there was not the expected compensatory increase in NADH levels (Franke et al., 1976; Pryor et al., 1992) (Table 2). Alternative attractive possibilities would be inhibition of $\mathrm{NAD}^{+}$synthesis or activation of $\mathrm{NAD}^{+}$catabolism. $\mathrm{Zn}^{2+}$ has been shown to both activate and inhibit different $\mathrm{NAD}^{+}$-catabolizing enzymes depending on the cell type and the conditions (Larsen et al., 1982; Kukimoto et al., 1996; Jorcke et al., 1997). A prominent NAD ${ }^{+}$-catabolizing enzyme is poly (ADP-ribose) synthetase (PARS), an enzyme likely involved in the detection and repair of single-stranded DNA breaks (Wang et al., 1995). We demonstrated here that three competitive inhibitors of PARS [niacinamide, benzamide, and 3-aminobenzamide (for review, see Szabo and Dawson, 1998)] all attenuate $\mathrm{Zn}^{2+}$ neurotoxicity (Fig. 2, Table 3), although these inhibitors also inhibit $\mathrm{NAD}^{+}$glycohydrylase, another enzyme that breaks down NAD ${ }^{+}$(Ziegler et al., 1996). PARS has been implicated as a mediator of neuronal damage after glutamate exposure (Zhang et al., 1994) or hypoxic insults (Eliasson et al., 
1997; Endres et al., 1997), consistent with a model in which glutamate receptor overactivation leads to the formation of nitric oxide and other reactive oxygen species (ROS), causing DNA strand breakage and PARS activation (for review, see Szabo and Dawson, 1998).

Cellular $\mathrm{Zn}^{2+}$ overload itself has been suggested to enhance ROS production (E. Y. Kim et al., 1999; Y. H. Kim et al., 1999a,b). We have found that the powerful ROS scavenger C3polar regioisomer buckministerfullerene (Dugan et al., 1997) was relatively ineffective at attenuating $\mathrm{Zn}^{2+}$-induced cortical neuronal death (L. L. Dugan and D. W. Choi, unpublished observations), and a recent study in cortical cultures did not see a general increase in cytosolic ROS in the first hour after toxic $\mathrm{Zn}^{2+}$ exposure (Sensi et al., 1999). Furthermore $\alpha$-keto butyrate, which blocks $\mathrm{H}_{2} \mathrm{O}_{2}$ hydroxyl radical-induced neuronal death (Desagher et al., 1997) by chemically inactivating $\mathrm{H}_{2} \mathrm{O}_{2}$ (Holleman, 1904; Desagher et al., 1997), was inactive against $\mathrm{Zn}^{2+}$ neurotoxicity in the present study (Table 3 ). Regardless of whether $\mathrm{Zn}^{2+}$ promotes ROS formation, the possibility that $\mathrm{Zn}^{2+}$ might somehow activate PARS is consistent with the recent observation that the high-affinity $\mathrm{Zn}^{2+}$ chelator $N, N^{\prime}, N^{\prime}$-tetrakis (2-pyridylmethyl) ethylenediamine inhibits PARS (Virag and Szabo, 1999) (although this observation could simply reflect a baseline requirement of PARS for a $\mathrm{Zn}^{2+}$ cofactor because it has a $\mathrm{Zn}^{2+}$ finger DNA binding domain).

The present proposal that indirect inhibition of GAPDH leading to energy failure is an important mediator of $\mathrm{Zn}^{2+}$-induced neuronal death does not exclude the possibility that $\mathrm{Zn}^{2+}$ may have other death-promoting actions. Direct inactivation of BDNF or NT-4/5 may be considered (Ross et al., 1997) but is unlikely in the present system because $\mathrm{Zn}^{2+}$ exposure did not block the phosphorylation of ERK1 and ERK2, downstream effectors of the TrkB neurotrophic signaling cascade. Activation of an extracellular acid sphingomyelinase producing the apoptotic signaling molecule ceramide (Schissel et al., 1996) is another possible toxic mechanism, although this enzyme is inactive at the physiological $\mathrm{pH}$ used in the present experiments.

The observed ability of pyruvate to restore $\mathrm{NAD}^{+}$to control levels at the expense of NADH provides a plausible explanation for its ability to counteract each of the stated effects of $\mathrm{Zn}^{2+}$ exposure on neuronal cultures (Table 2). The increase in extracellular lactate associated with pyruvate addition and the inhibition of pyruvate-induced neuroprotection by oxamate, an inhibitor of lactate dehydrogenase, are consistent with pyruvate generating $\mathrm{NAD}^{+}$from NADH through its conversion to lactate. However, niacinamide was not as effective as pyruvate in attenuating $\mathrm{Zn}^{2+}$-induced cell death (Fig. 2, Table 3), although it also restored $\mathrm{NAD}^{+}$levels (Table 2 ). Pyruvate also appeared markedly better than niacinamide in protecting neuronal processes (Fig. 2), raising a possibility that $\mathrm{Zn}^{2+}$ toxicity in processes may differ from that in soma. It is easily possible that pyruvate may have additional beneficial effects on $\mathrm{Zn}^{2+}$-injured neurons, such as enhancement of mitochondrial membrane potential (Kauppinen and Nicholls, 1986) or enhancement of PDH activity, which is reduced after global ischemia in vivo (Kobayashi and Neely, 1983; Zaidan and Sims, 1997).

The inability of lactate and $\beta$-hydroxy-butyrate to protect against $\mathrm{Zn}^{2+}$-induced death compared with their ability to substitute for glucose fits with the observation that they are used predominantly after prolonged periods of fasting (Owen et al., 1967; Robinson and Williamson, 1980), whereas $\mathrm{Zn}^{2+}$ may induce too rapid a block in glycolysis to allow the uptake and use of alternative substrates. Also, $\mathrm{Zn}^{2+}$-induced $\mathrm{NAD}^{+}$deficiency would be expected to inhibit the conversion of lactate to pyruvate by $\mathrm{LDH}$ and to inhibit the mitochondrial use of $\beta$-hydroxybutyrate. In contrast, oxaloacetate is effective at preventing $\mathrm{Zn}^{2+}$-induced neuronal death, perhaps because it can be converted to pyruvate (Lehninger et al., 1993).

The present observation that several energy substrates or modulators of energy pathway enzyme activity can attenuate $\mathrm{Zn}^{2+}$ induced neuronal death suggests several new approaches to ameliorating this death in the context of certain disease states.

\section{REFERENCES}

Assaf SY, Chung SH (1984) Release of endogenous $\mathrm{Zn}^{2+}$ from brain tissue during activity. Nature 308:734-736.

Berg JM, Shi Y (1996) The galvanization of biology: a growing appreciation for the roles of zinc. Science 271:1081-1085.

Canzoniero LM, Turetsky DM, Choi DW (1999) Measurement of intracellular free zinc concentrations accompanying zinc-induced neuronal death. J Neurosci 19: RC31.

Charton G, Rovira C, Ben-Ari Y, Leviel V (1985) Spontaneous and evoked release of endogenous $\mathrm{Zn}^{2+}$ in the hippocampal mossy fiber zone of the rat in situ. Exp Brain Res 58:202-205.

Choi DW, Koh JY (1998) Zinc and brain injury. Annu Rev Neurosci 21:347-375.

Danscher G, Howell G, Perez-Clausell J, Hertel N (1985) The dithizone, Timm's sulphide silver and the selenium methods demonstrate a chelatable pool of zinc in CNS. A proton activation (PIXE) analysis of carbon tetrachloride extracts from rat brains and spinal cords intravitally treated with dithizone. Histochemistry 83:419-422.

Desagher S, Glowinski J, Premont J (1997) Pyruvate protects neurons against hydrogen peroxide-induced toxicity. J Neurosci 17:9060-9067.

Dugan LL, Turetsky DM, Du C, Lobner D, Wheeler M, Almli CR, Shen CK, Luh TY, Choi DW, Lin TS (1997) Carboxyfullerenes as neuroprotective agents. Proc Natl Acad Sci USA 94:9434-9439.

Eliasson MJ, Sampei K, Mandir AS, Hurn PD, Traystman RJ, Bao J, Pieper A, Wang ZQ, Dawson TM, Snyder SH, Dawson VL (1997) Poly(ADP-ribose) polymerase gene disruption renders mice resistant to cerebral ischemia. Nat Med 3:1089-1095.

Endres M, Wang ZQ, Namura S, Waeber C, Moskowitz MA (1997) Ischemic brain injury is mediated by the activation of poly(ADP-ribose) polymerase. J Cereb Blood Flow Metab 17:1143-1151.

Franke H, Barlow CH, Chance B (1976) Oxygen delivery in perfused rat kidney: NADH fluorescence and renal functional state. Am J Physiol 231:1082-1089.

Frederickson CJ (1989) Neurobiology of zinc and zinc-containing neurons. Int Rev Neurobiol 31:145-238.

Frederickson CJ, Klitenick MA, Manton WI, Kirkpatrick JB (1983) Cytoarchitectonic distribution of zinc in the hippocampus of man and the rat. Brain Res 273:335-339.

Gutmann I, Wahlefeld AW (1974) L-(+)-Lactate: determination with lactate dehydrogenase and NAD. In: Methods of enzymatic analysis (Bergmeyer HU, ed), pp 1464-1468. New York: Academic.

Harrison NL, Gibbons SJ (1994) $\mathrm{Zn}^{2+}$ : an endogenous modulator of ligand- and voltage-gated ion channels. Neuropharmacology 33:935-952.

Haugland RP (1996) Handbook of fluorescent probes and research chemicals, Ed 6 (Spencer MTZ, ed), pp 530-540. Eugene, OR: Molecular Probes.

Holleman MAF (1904) Notice sur l'action de l'eau oxygénée sur les acides a-cétoniques et sur les dicétones 1.2. Recl Trav Chim Pays Bas Belg 23:169-171.

Howell GA, Welch MG, Frederickson CJ (1984) Stimulation-induced uptake and release of zinc in hippocampal slices. Nature 308:736-738.

Ikeda T, Kimura K, Morioka S, Tamaki N (1980) Inhibitory effects of $\mathrm{Zn}^{2+}$ on muscle glycolysis and their reversal by histidine. J Nutr Sci Vitaminol 26:357-366.

Jorcke D, Ziegler M, Schweiger M (1997) Characterization of hydrosoluble and detergent-solubilized forms of mitochondrial NAD + glycohydrolase from bovine liver. Adv Exp Med Biol 419:447-451.

Kauppinen RA, Nicholls DG (1986) Synaptosomal bioenergetics. The role of glycolysis, pyruvate oxidation and responses to hypoglycaemia. Eur J Biochem 158:159-165.

Kim EY, Koh JY, Kim YH, Sohn S, Joe E, Gwag BJ (1999) Z Zn ${ }^{2+}$ entry 
produces oxidative neuronal necrosis in cortical cell cultures. Eur J Neurosci 11:327-334.

Kim YH, Kim EY, Gwag BJ, Sohn S, Koh JY (1999a) Zinc-induced cortical neuronal death with features of apoptosis and necrosis: mediation by free radicals. Neuroscience 89:175-182.

Kim YH, Park JH, Hong SH, Koh JY (1999b) Nonproteolytic neuroprotection by human recombinant tissue plasminogen activator. Science 284:647-650.

Kobayashi K, Neely JR (1983) Effects of ischemia and reperfusion on pyruvate dehydrogenase activity in isolated rat hearts. J Mol Cell Cardiol 15:359-367.

Koh JY, Choi DW (1987) Quantitative determination of glutamate mediated cortical neuronal injury in cell culture by lactate dehydrogenase efflux assay. J Neurosci Methods 20:83-90.

Koh JY, Wie MB, Gwag BJ, Sensi SL, Canzoniero LM, Demaro J, Csernansky C, Choi DW (1995) Staurosporine-induced neuronal apoptosis. Exp Neurol 135:153-159.

Koh JY, Suh SW, Gwag BJ, He YY, Hsu CY, Choi DW (1996) The role of zinc in selective neuronal death after transient global cerebral ischemia. Science 272:1013-1016.

Krotkiewska B, Banas T (1992) Interaction of $\mathrm{Zn}^{2+}$ and $\mathrm{Cu}^{2+}$ ions with glyceraldehyde-3-phosphate dehydrogenase from bovine heart and rabbit muscle. Int J Biochem 24:1501-1505.

Kukimoto I, Hoshino S, Kontani K, Inageda K, Nishina H, Takahashi K, Katada T (1996) Stimulation of ADP-ribosyl cyclase activity of the cell surface antigen CD38 by zinc ions resulting from inhibition of its NAD + glycohydrolase activity. Eur J Biochem 239:177-182.

Larsen AG, Ostvold AC, Holtlund J, Kristensen T, Laland SG (1982) The inhibitory effect of $\mathrm{Zn}^{2+}$ on poly(ADP-ribose) polymerase activity and its reversal. Biochem J 203:511-513.

Lehninger AL, Nelson DL, Cox MM (1993) Principles of Biochemistry. New York: Worth.

Link TA, von Jagow G (1995) Zinc ions inhibit the QP center of bovine heart mitochondrial bc1 complex by blocking a protonatable group. J Biol Chem 270:25001-25006.

Lust WD, Feussner GK, Barbehenn EK, Passonneau JV (1981) The enzymatic measurement of adenine nucleotides and P-creatine in picomole amounts. Anal Biochem 110:258-266.

Manev H, Kharlamov E, Uz T, Mason RP, Cagnoli CM (1997) Characterization of zinc-induced neuronal death in primary cultures of rat cerebellar granule cells. Exp Neurol 146:171-178.

Martell AM, Smith RM (1995) Critically selected stability constants of metal complexes, p 411. Gaithersburg, MD: National Institute of Standards and Technology.

Michal GB, Beutler HO (1974) D-Fructose-1,6-P2, dihydroxyacetone phosphate and D-glyceraldehyde-3-phosphate. In: Methods of enzymatic analysis (Bergmeyer HU, ed), pp 1314-1319. New York: Academic.

Owen OE, Morgan AP, Kemp HG, Sullivan JM, Herrera MG, Cahill Jr GF (1967) Brain metabolism during fasting. J Clin Invest 46:1589-1595.

Poolman B, Bosman B, Kiers J, Konings WN (1987) Control of glycolysis by glyceraldehyde-3-phosphate dehydrogenase in Streptococcus cremoris and Streptococcus lactis. J Bacteriol 169:5887-5890.

Pryor WA, Arbour NC, Upham B, Church DF (1992) The inhibitory effect of extracts of cigarette tar on electron transport of mitochondria and submitochondrial particles. Free Radic Biol Med 12:365-372.

Robinson AM, Williamson DH (1980) Physiological roles of ketone bodies as substrates and signals in mammalian tissues. Physiol Rev 60:143-187.

Ross GM, Shamovsky IL, Lawrance G, Solc M, Dostaler SM, Jimmo SL, Weaver DF, Riopelle RJ (1997) Zinc alters conformation and inhibits biological activities of nerve growth factor and related neurotrophins. Nat Med 3:872-878.

Rovetto MJ, Lamberton WF, Neely JR (1975) Mechanisms of glycolytic inhibition in ischemic rat hearts. Circ Res 37:742-751.

Sander BJ, Oelshlegel FJ Jr, Brewer GJ (1976) Quantitative analysis of pyridine nucleotides in red blood cells: a single-step extraction procedure. Anal Biochem 71:29-36.

Schissel SL, Schuchman EH, Williams KJ, Tabas I (1996) $\mathrm{Zn}^{2+}$-stimulated sphingomyelinase is secreted by many cell types and is a product of the acid sphingomyelinase gene. J Biol Chem 271:18431-18436.

Schurr A, Payne RS, Miller JJ, Rigor BM (1997) Brain lactate, not glucose, fuels the recovery of synaptic function from hypoxia upon reoxygenation: an in vitro study. Brain Res 744:105-111.

Sensi SL, Canzoniero LM, Yu SP, Ying HS, Koh JY, Kerchner GA, Choi DW (1997) Measurement of intracellular free zinc in living cortical neurons: routes of entry. J Neurosci 17:9554-9564.

Sensi SL, Yin HZ, Carriedo SG, Rao SS, Weiss JH (1999) Preferential $\mathrm{Zn}^{2+}$ influx through $\mathrm{Ca}^{2+}$-permeable AMPA/kainate channels triggers prolonged mitochondrial superoxide production. Proc Natl Acad Sci USA 96:2414-2419.

Sheline CT, Choi DW (1997) Two strategies for attenuating zinc neurotoxicity on cortical neurons. Soc Neurosci Abstr 23:2255.

Sheline CT, Choi DW (1998) Neuronal death in cultured murine cortical cells is induced by inhibition of GAPDH and triosephosphate isomerase. Neurobiol Dis 5:47-54.

Skulachev VP, Chistyakov VV, Jasaitis AA, Smirnova EG (1967) Inhibition of the respiratory chain by zinc ions. Biochem Biophys Res Commun 26:1-6.

Smart TG, Xie X, Krishek BJ (1994) Modulation of inhibitory and excitatory amino acid receptor ion channels by zinc. Prog Neurobiol 42:393-341.

Szabo C, Dawson VL (1998) Role of poly(ADP-ribose) synthetase in inflammation and ischaemia-reperfusion. Trends Pharmacol Sci 19:287-298.

Tilton WM, Seaman C, Carriero D, Piomelli S (1991) Regulation of glycolysis in the erythrocyte: role of the lactate/pyruvate and NAD/ NADH ratios. J Lab Clin Med 118:146-152.

Tonder N, Johansen FF, Frederickson CJ, Zimmer J, Diemer NH (1990) Possible role of zinc in the selective degeneration of dentate hilar neurons after cerebral ischemia in the adult rat. Neurosci Lett 109:247-252.

Vallee BL, Falchuk KH (1993) The biochemical basis of zinc physiology. Physiol Rev 73:79-118.

Virag L, Szabo C (1999) Inhibition of poly(ADP-ribose) synthetase (PARS) and protection against peroxynitrite-induced cytotoxicity by zinc chelation. Br J Pharmacol 126:769-777.

Wang ZQ, Auer B, Stingl L, Berghammer H, Haidacher D, Schweiger M, Wagner EF (1995) Mice lacking ADPRT and poly(ADP-ribosyl)ation develop normally but are susceptible to skin disease. Genes Dev 9:509-520.

Weil M, Jacobson MD, Coles HS, Davies TJ, Gardner RL, Raff KD, Raff MC (1996) Constitutive expression of the machinery for programmed cell death. J Cell Biol 133:1053-1059.

Weiss JH, Hartley DM, Koh JY, Choi DW (1993) AMPA receptor activation potentiates zinc neurotoxicity. Neuron 10:43-49.

Wong C, Rodriguez-Paez L, Nogueda B, Perez A, Baeza I (1997) Selective inhibition of the sperm-specific lactate dehydrogenase isozyme-C4 by $N$-isopropyl oxamate. Biochim Biophys Acta 1343:16-22.

Yokoyama M, Koh J, Choi DW (1986) Brief exposure to zinc is toxic to cortical neurons. Neurosci Lett 71:351-355.

Zaidan E, Sims NR (1997) Reduced activity of the pyruvate dehydrogenase complex but not cytochrome c oxidase is associated with neuronal loss in the striatum following short-term forebrain ischemia. Brain Res 772:23-28.

Zhang J, Dawson VL, Dawson TM, Snyder SH (1994) Nitric oxide activation of poly(ADP-ribose) synthetase in neurotoxicity. Science 263:687-689.

Ziegler M, Jorcke D, Zhang J, Schneider R, Klocker H, Auer B, Schweiger M (1996) Characterization of detergent-solubilized beef liver mitochondrial NAD+ glycohydrolase and its truncated hydrosoluble form. Biochemistry 35:5207-5212. 